\title{
Article \\ Effects of Simulated Gastric Acid Exposure on Surface Topography, Mechanical and Optical Features of Commercial CAD/CAM Ceramic Blocks
}

\author{
Ioana Ligia Pîrvulescu ${ }^{1}$, Daniel Pop ${ }^{1,2}$, Elena-Alina Moacă ${ }^{3,4, * \mathbb{D}}$, Ciprian-Valentin Mihali ${ }^{5,6}$, Codruța Ille $^{1}$ \\ and Anca Jivănescu 1,2 (D)
}

check for

updates

Citation: Pîrvulescu, I.L.; Pop, D.; Moacă, E.-A.; Mihali, C.-V.; Ille, C.; Jivănescu, A. Effects of Simulated Gastric Acid Exposure on Surface Topography, Mechanical and Optical Features of Commercial CAD/CAM Ceramic Blocks. Appl. Sci. 2021, 11, 8703. https://doi.org/10.3390/ app11188703

Academic Editor: Yong-Deok Kim

Received: 31 July 2021

Accepted: 14 September 2021

Published: 18 September 2021

Publisher's Note: MDPI stays neutral with regard to jurisdictional claims in published maps and institutional affiliations.

Copyright: (C) 2021 by the authors Licensee MDPI, Basel, Switzerland. This article is an open access article distributed under the terms and conditions of the Creative Commons Attribution (CC BY) license (https:// creativecommons.org/licenses/by/ $4.0 /)$.
1 Department of Prosthodontics, Faculty of Dental Medicine, “Victor Babes” University of Medicine and Pharmacy, Revolutiei Ave. 1989, No. 9, 300580 Timișoara, Romania; pirvulescu.ioana@umft.ro (I.L.P.); pop.daniel@umft.ro (D.P.); ille.codruta@umft.ro (C.I.); jivanescu.anca@umft.ro (A.J.)

2 TADERP Reseach Center-Advanced and Digital Techniques for Endodontic, Restorative and Prosthetic Treatment, "Victor Babeș" University of Medicine and Pharmacy, Revolutiei Ave. 1989, No. 9, 300041 Timişoara, Romania

3 Department of Toxicology and Drug Industry, Faculty of Pharmacy, "Victor Babeș" University of Medicine and Pharmacy Timisoara, 2nd Eftimie Murgu Square, 300041 Timisoara, Romania

4 Research Centre for Pharmaco-Toxicological Evaluation, "Victor Babeș" University of Medicine and Pharmacy, 2nd Eftimie Murgu Square, 300041 Timișoara, Romania

5 The Institute of Life Sciences, “Vasile Goldis” Western University of Arad, Liviu Rebreanu Street, No. 86, 310414 Arad, Romania; mihaliciprian@uvvg.ro

6 The Molecular Research Department, Research and Development Station for Bovine Arad, Bodrogului Street, No. 32, 310059 Arad, Romania

* Correspondence: alina.moaca@umft.ro; Tel.: +40-745-762-600

Featured Application: Degradation of the material used for prosthetic rehabilitation leads to more or less serious problems, namely impairment of aesthetics, craniofacial disorders, discomfort especially during chewing food, which will be increasingly reduced, leading in the end to fatigue of the masticatory muscles. The most harmful for the dental structure is considered gastric juice. This acidic substance produce degradation both enamel, as well as some restorative materials. In this context, the present work consists in evaluating the surface topography and mechanical properties of some CAD/CAM monolithic materials (already existing on the market), used for prosthetic restoration, thus helping dentists to choose those ceramic materials that are resistant to the effects of gastric juice.

Abstract: Gastric acid exposure produces tooth structure demineralization and dental ceramic degradation. The most affected patients are those who suffer from gastroesophageal reflux disease, bulimia nervosa, and pregnant women with prolonged severe nausea. In order to protect this kind of patient, the purpose of this study was to determine whether simulated gastric acid exposure leads to microstructural changes in surface topography, hardness, color changes, and translucency of some ceramic materials, which are already on the market. Forty disks (Triluxe Forte, Cerasmart, Enamic and Empress CAD) were analyzed before and after immersion in simulated gastric acid juice, in terms of microhardness, surface roughness, translucency, and surface morphology using scanning electron microscopy. Color change was assessed by using a spectrophotometer based on CIELab parameters and the results showed that, after exposure, $\Delta E_{a b}$ remained under the threshold of acceptability and perceptibility. In terms of microhardness, Cerasmart is the only material that did not undergo changes after immersion. SEM images illustrated observable changes surface topography after acid exposure for all the tested materials. In conclusion, Triluxe Forte suffered the most important changes after simulated gastric acid juice exposure, and Cerasmart proved to be the least affected material.

Keywords: CAD/CAM; ceramic materials; gastric acid; surface roughness; microhardness; surface morphology 


\section{Introduction}

The evolution of dentistry has advanced and will continue to advance through the appearance of intelligent materials on the market, designed to contribute to oral health care and, thus, to the improvement of quality of life. To date, many types of dental materials have been generated and are available for clinical applications. Resin based-composites and materials conjugated in cements and metals have been widely produced to replace missing tooth structures and mimic the aesthetic characteristics of tooth structures [1-7]. Resin based-composites with different inorganic reinforcement particles are commonly commercialized due to their excellent mechanical and physicochemical properties, such as their high strength, bright surface, low surface roughness, resistance to wear/fracture, and adherence to dental tissues [8-10]. Therapeutic restorative materials are used for minimally invasive and a traumatic restorative dentistry and, in this context, the development of new restorative materials that can mimic the mechanical, physicochemical and aesthetics features of dentin and enamel are necessary [11,12].

In the recent years, computer-aided design and computer-aided manufacturing (CADCAM) systems have allowed monolithic restorations to be made in a single session. CAD-CAM restorative materials have been widely used in dentistry due to their stable quality of materials and lower costs. CAD-CAM technology satisfies aesthetic demands, such as color and translucency reproduction, and even chromatic stability under clinical conditions [13-15]. While most studies have reported extensive details on the positive characteristics of these materials [16-22], few studies have investigated the surface behavior of these materials in contact with endogenous (salivary enzymes, gastric juice) or exogenous (acidic beverages) substances. These acidic elements have been correlated with severe dental structure degradation and restoration, most probably due to their acidic $\mathrm{pH}[23,24]$. Regardless of the origin, these acidic substances attack the surface of the tooth, as well as the surface of CAD-CAM restorative materials, changing their structure over time [25-27]. It was established that gastric juice produce more severe degradation of dental structures than acidic beverages [28-30]. Gastric juice comes into contact with the oral cavity as a result of gastroesophageal reflux disease or bulimia nervosa [31-33]. Even the case of pregnant women with prolonged severe nausea episodes during pregnancy can face the issue gastric juices [23].

Dental erosion, defined as a progressive loss of hard dental tissues due to chemical processes, without the action of bacteria, can be correlated with the intrinsic and/or extrinsic origin of acid. The results of chemical erosion consist in hard, polished, and smooth depression of a tooth's surface [34]. Extrinsic tooth erosion is mainly due to the consumption of low-pH beverages and foods. It may also be due to the use of medications, such as aspirin, which is a low $\mathrm{pH}$ drug [35].

All-ceramic restorations that offer biocompatibility and aesthetics may be affected by gastric acid, although less intensely than enamel [31]. Chemical degradation can lead to microstructural changes in surface topography, which can affect light reflection, color perception, and stability [36]. The knowledge of how ceramic materials react to gastric acid can help a dentist in selecting suitable materials for prosthetic restorations for the special patients mentioned above, though not limited to them. Although the literature reports on the effects of acidic elements on the surface of different restorative materials [25,31,37-41], to the best of authors' knowledge, no study has yet to compare, under the same conditions, these four monolithic CAD-CAM materials: feldspathic ceramic, nanoceramic resin, hybrid ceramic, and leucite-reinforced glass ceramic.

In this regard, the purpose of the present in vitro study was to evaluate the effects of surface topography and the mechanical features of different restorative computer-aided designs and computer-aided manufacturing (CAD-CAM) dental materials after exposure to simulated gastric juices. We assumed that with these materials, already available on the market, the exposure to simulated gastric juice for $18 \mathrm{~h}$ would not change the surface topography nor the mechanical properties of the monolithic materials under consideration. 


\section{Materials and Methods}

\subsection{Specimens Preparation}

The monolithic materials tested in this in vitro study along with their compositions are listed in Table 1 . Forty disks ( $n=10$ /subgroup) of feldspathic ceramic (Triluxe Forte, VITA, Zahnfabrik), nanoceramic resin (Cerasmart, GC Europe), hybrid ceramic (Enamic, VITA, Zahnfabrik), and leucite-reinforced glass ceramic (Empress CAD, Ivoclar, Vivadent) were used in this study.

Table 1. The composition, manufacturer, and classification of the tested monolithic materials.

\begin{tabular}{|c|c|c|c|}
\hline Material & Classification & Composition & Manufacturer \\
\hline Triluxe Forte & feldspathic ceramics & $\begin{array}{c}\mathrm{SiO}_{2} 56-64 \% ; \mathrm{Al}_{2} \mathrm{O}_{3} 20-23 \% ; \mathrm{Na}_{2} \mathrm{O} 6-9 \% ; \mathrm{K}_{2} \mathrm{O} \\
6-8 \% ; \mathrm{CaO} 0.3-0.6 \% ; \mathrm{TiO}_{2} 0.0-0.1 \%\end{array}$ & $\begin{array}{l}\text { VITA Zahnfabrik (Bad Säckingen, } \\
\text { Germany) }\end{array}$ \\
\hline Cerasmart & nanoceramic resin & $71 \%$ Silica and barium glass nanoparticles & GC Europe (Tokyo, Japan) \\
\hline Enamic & $\begin{array}{l}\text { hybrid ceramic with a } \\
\text { dual network structure }\end{array}$ & $\begin{array}{c}\mathrm{SiO}_{2} 5-63 \% ; \mathrm{Al}_{2} \mathrm{O}_{3} 20-23 \% ; \mathrm{Na}_{2} \mathrm{O} 6-11 \% ; \mathrm{K}_{2} \mathrm{O} \\
4-6 \% ; \mathrm{B}_{2} \mathrm{O}_{3} 0.5-2 \% ; \mathrm{CaO}<1 \% ; \mathrm{TiO}_{2}<1 \%\end{array}$ & $\begin{array}{c}\text { VITA Zahnfabrik (Bad Säckingen, } \\
\text { Germany) }\end{array}$ \\
\hline Empress CAD & $\begin{array}{l}\text { leucite-reinforced } \\
\text { glass-ceramic }\end{array}$ & $\begin{array}{c}\mathrm{SiO}_{2} 60-65 \% ; \mathrm{Al}_{2} \mathrm{O}_{3} 16-20 \% ; \mathrm{K}_{2} \mathrm{O} 10-14 \% \\
\mathrm{Na}_{2} \mathrm{O} 3.5-6.5 \%\end{array}$ & $\begin{array}{l}\text { Ivoclar Vivadent (Zurich, } \\
\text { Schwitzerland) }\end{array}$ \\
\hline
\end{tabular}

CAD-CAM blocks were milled into disks ( $1 \mathrm{~mm}$ thick, $14 \mathrm{~mm}$ long, and $12 \mathrm{~mm}$ wide), with a precision saw (IsoMet 1000-Buehler, Lake Bluff, IL, USA) and a special disk used for cutting structured ceramics (IsoMet Diamond Wafering Blade, 15LC-Buehler, Lake Bluff, IL, USA), at a speed of 100 rotations per minute. The resulting ceramic disks were finished with abrasive paper (Klingspor, Haiger, Germany) using different granulations (P240, P400, P800, P1000, and P1200). All analyses were carried out before and after gastric acid exposure.

\subsection{Immersion of Ceramic Disks in Simulated Gastric Acid Solution}

Specimens were individually immersed for $18 \mathrm{~h}$ in $5 \mathrm{~mL}$ of simulated gastric acid solution and stored in an incubator (Cultura, Ivoclar, Zurich, Schwitzerland) at $37^{\circ} \mathrm{C}$. The simulated gastric acid solution was prepared with $0.113 \%(0.06 \mathrm{M})$ hydrochloric acid $(\mathrm{HCl})$ solution in deionized water and adjusted to $\mathrm{pH} 1.2$ [29,42]. Considering that a patient suffering from bulimia has, on average, vomits 3 times daily, and the contact time between vomit and restoration material is under $1 \mathrm{~min}$ [40], it can be estimated that the immersion time used corresponds with 2 years of gastric juice exposure.

\subsection{Investigation of Optical Parameters}

Color parameters were analyzed using a spectrophotometer (VITA Easyshade V, Bad Säckingen, Germany). The CIELab metric values were recorded and stored for color difference measurements after the discs were immersed in the simulated gastric acid solution. Calibration of the spectrophotometer was done before each specimen's measurement.

After immersion, the disks were rinsed with water and the CIELab metric values were again determined. Mean values of $L^{*}, a^{*}, b^{*}$ were compared with the data gathered prior to the immersion. The total color change $(\Delta E)$ was calculated for each monolithic material using the following equation:

$$
\Delta E_{a b}=\sqrt{\left[\left(\Delta L^{*}\right)^{2}+\left(\Delta a^{*}\right)^{2}+\left(\Delta b^{*}\right)^{2}\right]}
$$

where $L^{*}$-the lightness coefficient, ranging from 0 (black) to 100 (white); $a^{*}$-the shade of redness (positive values) and greenness (negative values); $b^{*}$ - denotes yellowness (positive values) and blueness (negative values).

Relative values of $\Delta L^{*}, \Delta a^{*}, \Delta b^{*}$ corresponded to differences before and after immersion. Color differences were classified as follows: $\Delta E>1$ the color change can be detected 
visually, but is acceptable; $\Delta E>3.3$ the color changes are clinically unacceptable [43] and $\Delta E<1$ are considered undetectable color changes to the human eye [44].

\subsection{Evaluation of Translucency Parameters}

Translucency is the ability of a material to transmit light and it can be calculated by the translucency parameter (TP), applying the following equation [45]:

$$
T P=\sqrt{\left(L_{B}^{*}-L_{W}^{*}\right)^{2}+\left(a_{B}^{*}-a_{W}^{*}\right)^{2}+\left(b_{B}^{*}-b_{W}^{*}\right)^{2}}
$$

where the $B$ and $W$ subscripts, refer to color coordinates over black and white backgrounds.

\subsection{Microhardness Measurements}

Microhardness was measured using a Digital Display Vickers (Novotest-TB-MCV1A, Novotest, Meschede, Germany) micro-hardness tester. A load of $1000 \mathrm{~g}$ was applied without impact. The diamond indenter was held in place for $15 \mathrm{~s}$. The two indentation diagonals were measured. Four indentations were made in each specimen, before and after immersion ( $\mathrm{HVi}$ and $\mathrm{HVf}$, respectively). Indentation dimensions were measured using the eyepiece of a microscope and the hardness values were obtained from standard tables.

\subsection{Surface Roughness Measurements}

Surface roughness $(\mathrm{Ra})$ was assessed using a profilometer (Perthometer M2, Mahr, Gottingen, Germany) at baseline (Ra1) and after the immersion time (Ra2). In order to measure the roughness, a diamond stylus with a $5-\mu \mathrm{m}$ tip radius was used. The stylus was moved across the ceramic disc surface under a constant load of $3.9 \mathrm{nM}$ at a speed of $0.12 \mathrm{~mm} / \mathrm{s}$. The readings made before and after simulated acid exposure $(18 \mathrm{~h})$ were carried out on the same location and the procedure was repeated 4 times for each specimen.

\subsection{Scanning Electron Microscopy (SEM) and Energy Dispersive X-ray Spectroscopy (EDX) Analysis}

A scanning electron microscope was used to examine the surface microstructure and was used to determine the degree of damage on the ceramic surface after exposure to gastric acid juice. SEM analysis was carried out on an FEI Quanta 250 microscope (Eindhoven, The Netherlands). SEM analysis parameters were HV mode, $30 \mathrm{kV}$, ETD (Everhart-Thornley detector for secondary electrons), with two magnification orders, one for a general overview $(100 \times)$ of the image/measurements and another for a higher surface topography $(5000 \times)$ for regions of interest. The observations were made before and after immersion. EDX analysis (energy dispersive X-ray spectroscopy) was carried out with an EDAX system (Apollo X detector, Ametek, Mahwah, NJ, USA). For better conductivity and to acquire high resolution SEM imaging, each specimen was covered with gold: $4 \mathrm{~nm} /$ deposition, 3 times, using an AutoAgar Sputter Coater (Agar Scientific Ltd., Essex, UK). The identified chemical species were expressed as atomic relative percent $(\mathrm{At} \%)$ and weight relative percent $(\mathrm{Wt} \%)$.

\subsection{Statistical Analysis}

The statistical programs applied in the present study were one-way analysis of variance (ANOVA) followed by Tukey's test, employed to evaluate the statistically significant differences, before and after immersion in gastric acid solution $\left({ }^{* * *} p<0.001\right)$.

\section{Results}

\subsection{Optical Parameters}

Table 2 shows the values regarding the color change for each material and the comparisons between the four monolithic materials were taken into account, as depicted in Figure 1. 
Table 2. Color change $(\Delta E)$ calculated after gastric acid exposure \pm standard deviation.

\begin{tabular}{ccccc}
\hline & Cerasmart & Enamic & Empress CAD & Triluxe Forte \\
\hline After 18 h of exposure & $0.71 \pm 0.3$ & $0.81 \pm 0.18$ & $1.23 \pm 0.58$ & $1.72 \pm 0.87$ \\
\hline
\end{tabular}

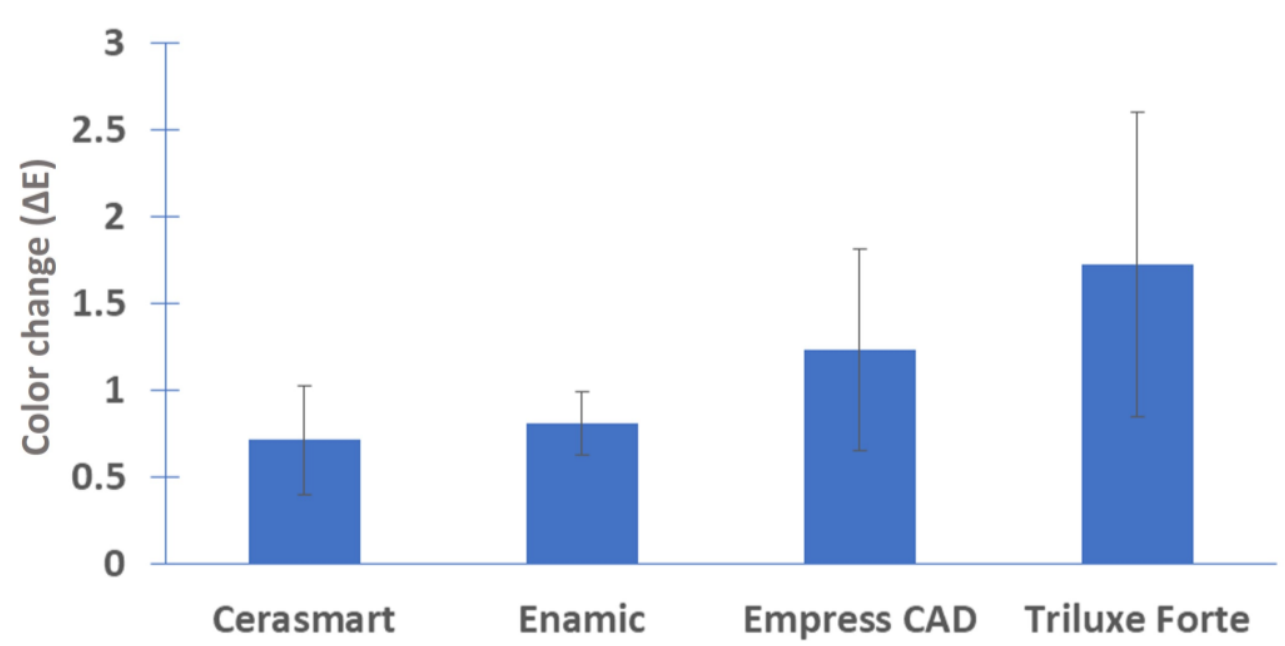

Figure 1. Comparison between the four CAD-CAM monolithic materials, after $18 \mathrm{~h}$ of simulated gastric acid solution exposure.

The results show that no statistically significant difference was found between Cerasmart and Enamic after $18 \mathrm{~h}$ of immersion in simulated gastric acid solution. Both monolithic CAD-CAM restorative materials had $\Delta E<1$, which meant that the color change was undetectable by the human eye. Regarding the Empress CAD material, the difference between before exposure and after was also statistically insignificant. The $\Delta E$ value was $>1$, which means that the color change could be detected visually, but was acceptable. The optical parameters showed that the feldspathic ceramic (Triluxe Forte) was the only monolithic material that underwent a slight discoloration after exposure to the simulated gastric acid solution, with a color change that was acceptable and visually detected.

\subsection{Translucency Parameters}

The translucency parameters of the disks did not suffer any drastic changes after $18 \mathrm{~h}$ of immersion, for any of the tested materials, as can be seen in Figure 2.

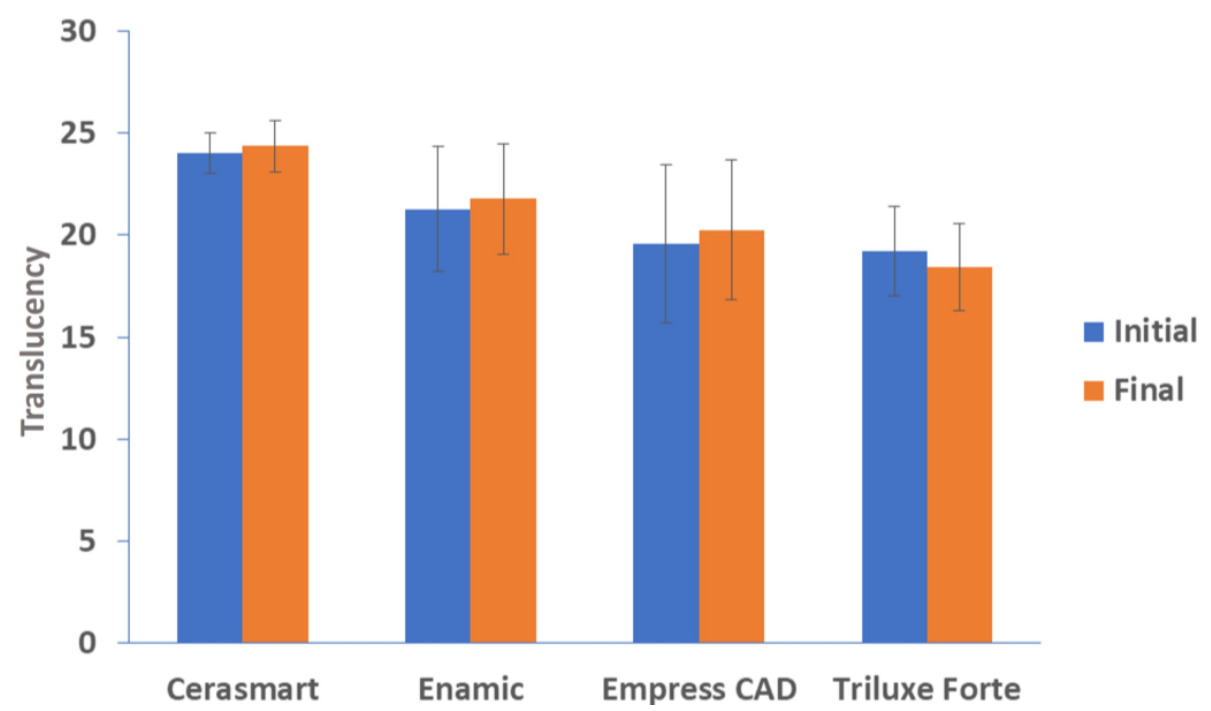

Figure 2. Comparison between the translucency parameters of four CAD-CAM monolithic materials, before exposure (initial) and after exposure (final). 
The values of the analysis results are shown in Table 3. Mean and standard deviation were calculated for each material using ANOVA and Tukey's test. According to Tukey's test, the results are significant at $p \leq 0.05$. The results obtained in this study for all monolithic materials tested proved to be statistically insignificant.

Table 3. Translucency parameters, before and after $18 \mathrm{~h}$ of simulated gastric acid solution exposure: mean and standard deviation.

\begin{tabular}{ccccc}
\hline \multirow{2}{*}{$\begin{array}{c}\text { Monolithic } \\
\text { Material }\end{array}$} & Before & After & Before & After \\
\cline { 2 - 5 } & 24.03 & 24.36 & 0.98 & 1.25 \\
Cerasmart & 21.26 & 21.76 & 3.06 & 2.72 \\
Enamic & 19.56 & 20.74 & 3.87 & 3.42 \\
Empress CAD & 18.43 & 2.19 & 2.11 \\
Triluxe Forte & 19.51 & & & \\
\hline
\end{tabular}

\subsection{Microhardness Test}

Regarding microhardness investigations, there was a significant decrease in the tested CAD-CAM monolithic materials, except for Cerasmart, which retained the same parameters. The monolithic material that suffered the largest change in terms of microhardness was Triluxe Forte, as can be observed in Figure 3.

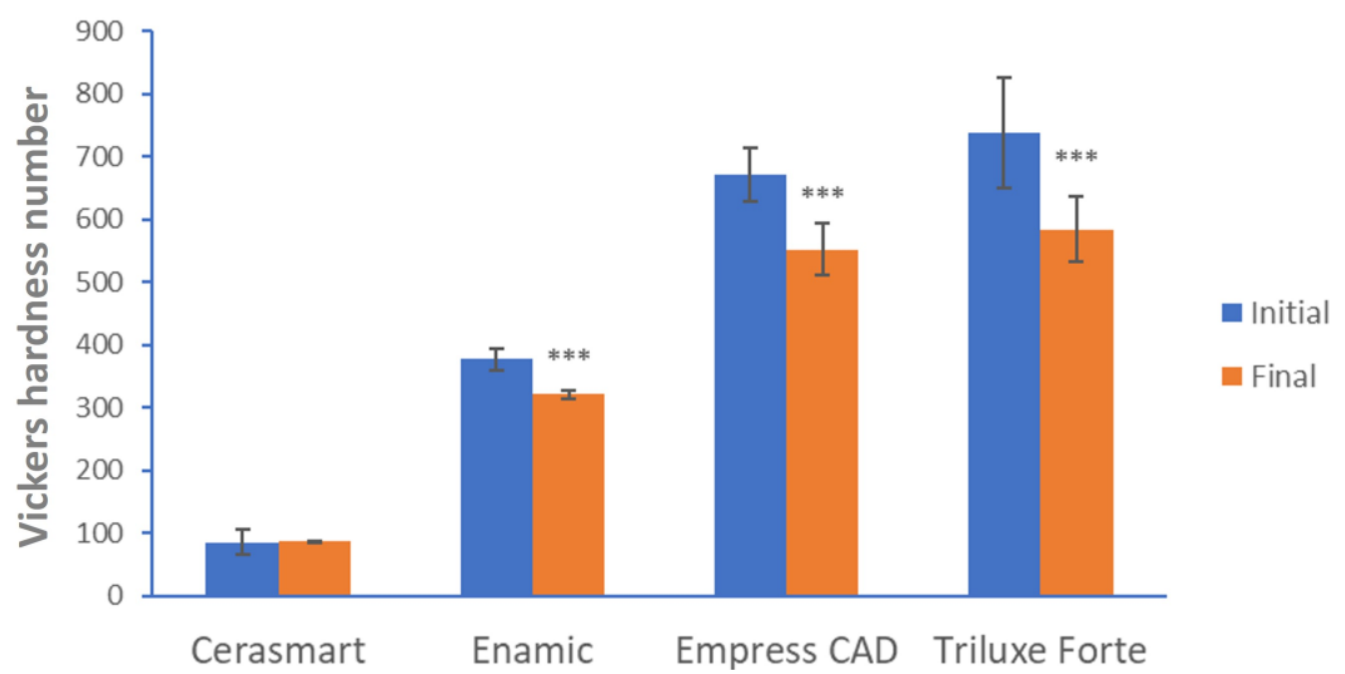

Figure 3. Comparison of microhardness values, before and after $18 \mathrm{~h}$ of immersion in simulated gastric acid solution. One-way ANOVA analysis was applied to determine the statistical differences between monolithic materials, followed by the Tukey's test $(* * *<0.001)$.

The results obtained regarding the microhardness test are highly significant, $p<0.001$ for Enamic, Empress CAD, and Triluxe Forte. For the monolithic material Cerasmart, a $p$ value of 0.85 was obtained, denoted that the result was statistically insignificant.

\subsection{Surface Roughness Results}

The surface roughness mean and standard deviations are shown in Table 4. The results obtained denote that there were no significant differences for Cerasmart, Enamic, and Empress CAD. Triluxe Forte, had statistically significant differences and exhibited the most change in terms of surface roughness, which can reduce the strength of the restoration; a nonuniform stress distribution and can lead to fracture. The roughness results, after $18 \mathrm{~h}$ of immersion in simulated gastric acid solution were: Triluxe Forte $>$ Enamic $>$ Cerasmart $>$ Empress CAD. 
Table 4. Mean and standard deviations (SD) of surface roughness test ( $\mu \mathrm{m})$, before (Ra1) and after (Ra2) simulated gastric acid solution exposure.

\begin{tabular}{ccc}
\hline Material & Ra1 & Ra2 \\
\hline Triluxe Forte & $0.81 \pm 0.15$ & $1.3 \pm 0.08$ \\
Cerasmart & $0.89 \pm 0.06$ & $0.92 \pm 0.06$ \\
Enamic & $0.92 \pm 0.07$ & $0.98 \pm 0.08$ \\
Empress CAD & $0.63 \pm 0.07$ & $0.72 \pm 0.06$ \\
\hline
\end{tabular}

\subsection{SEM-EDX Analysis}

All the tested monolithic CAD-CAM materials were subjected to electronic microscopy. The images of the morphology of the Triluxe Forte and Cerasmart materials, before and after $18 \mathrm{~h}$ of exposure to simulated gastric acid solution, are presented in Figure 4 . The morphological evaluation conducted in the present study revealed that all monolithic materials exhibited observable changes in surface topography after simulated gastric acid exposure.
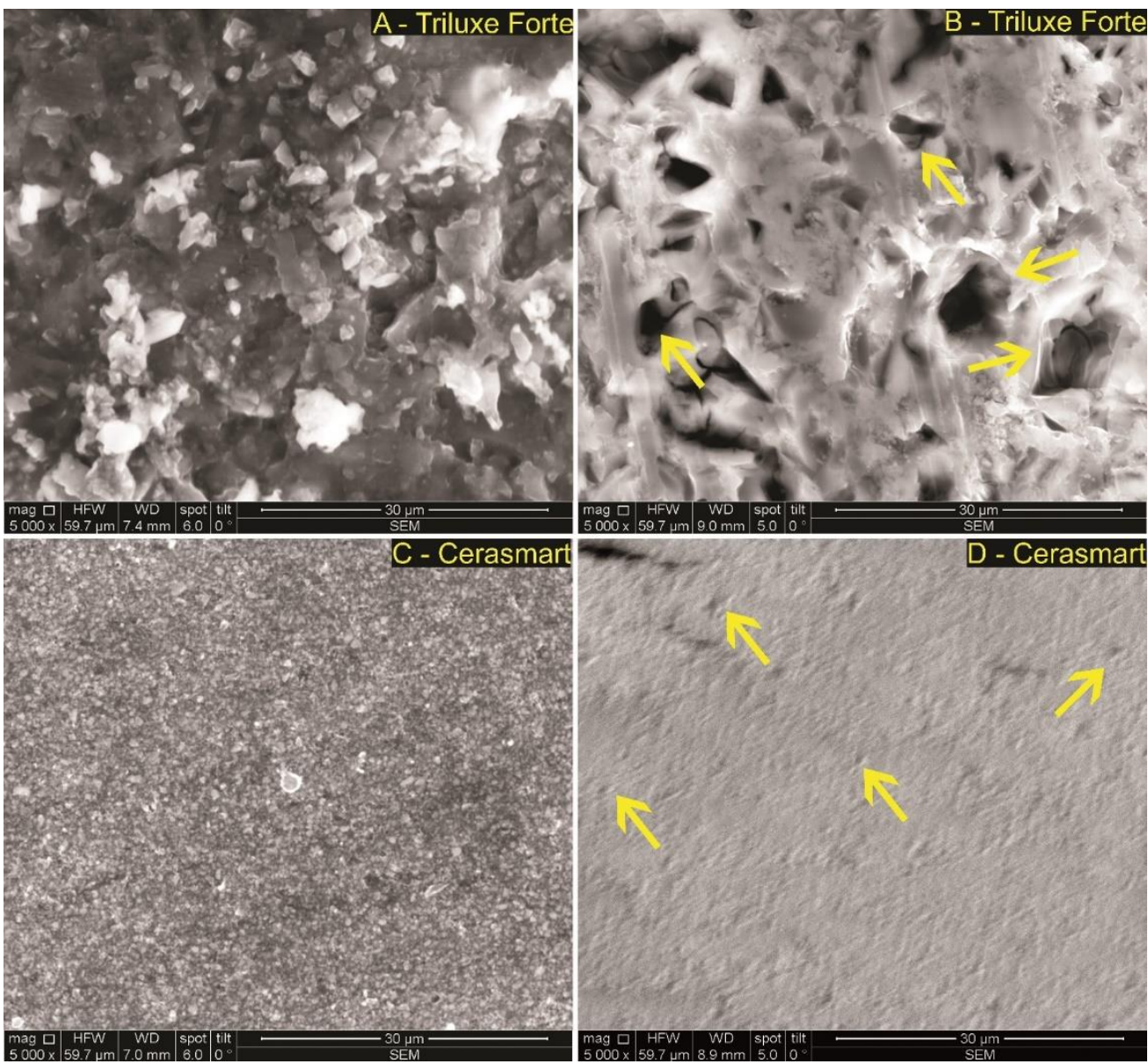

Figure 4. SEM images of Triluxe Forte and Cerasmart ((A,C) - before and (B,D)—after exposure to simulated gastric acid solution) at $5000 \times$ magnification and a $99.7 \mu \mathrm{m}$ horizontal field width. The yellow arrows represent changes that occurred after simulated gastric acid exposure. The nonexposed samples to simulated gastric acid solution exhibited a micro-roughness surface $(\mathbf{C})$ and an increased roughness in sample (A). The exposed samples to simulated gastric acid solution (B,D) presented a clear surface with a polished aspect with obvious pores indicated by yellow arrows (B) and a lack of micro-roughness surface aspect with a few pores indicated also by yellow arrows (D). 
An irregular surface, pores, and grooves of different sizes were observed in the feldspathic ceramic (Figure 4A-Triluxe Forte) before immersion. After immersion, the material surface showed larger grooves and less irregularities (Figure 4B).

Cerasmart is a hybrid ceramic, composed of a resin matrix with silica and barium glass nanoparticles. The glassy phase might be attacked less by gastric acid than the resin phase, which leads to an increase in surface roughness.

In Figure 5, SEM images of Enamic and Empress monolithic materials are shown. The non-exposed samples to simulated gastric acid solution exhibited a rough surface lacking in sharpness (Figure 5A and the presence of a slight surface matrix appearance (Figure 5C). The exposed samples to simulated gastric acid solution (Figure 5B,D) presented, in both samples, surfaces that were rough and obvious, the surface structures were sharp compared to the control samples (non-exposed), and are highlighted by yellow arrows.
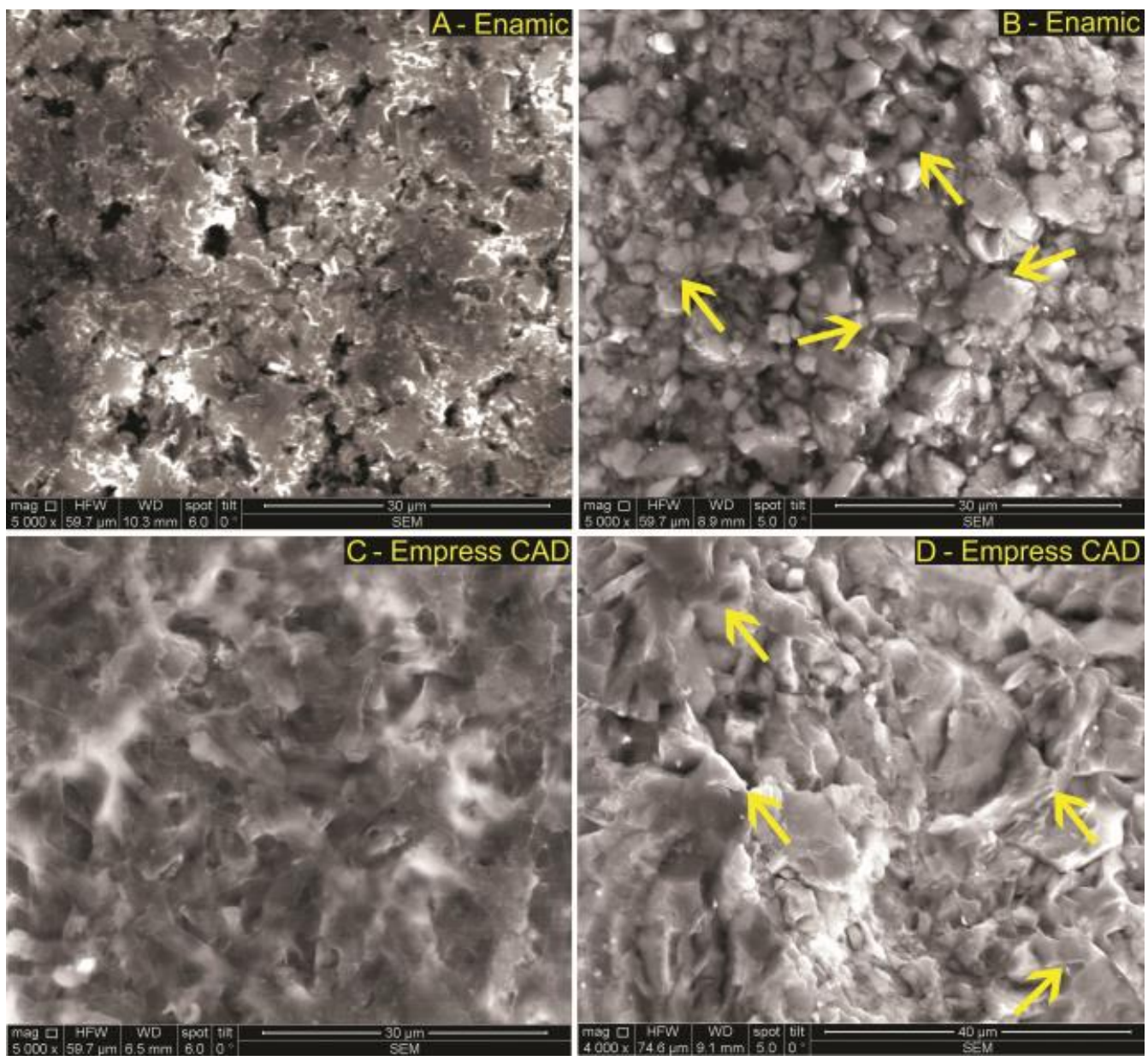

Figure 5. SEM images of Enamic and Empress CAD $(\mathbf{A}, \mathbf{C})$ - before and $(\mathbf{B}, \mathbf{D})$ - after exposure to simulated gastric acid Scheme 5000× magnification and a 59.7-74.6 $\mu \mathrm{m}$ horizontal field width. The yellow arrows represent the changes that occurred after simulated gastric acid exposure.

Enamic is a ceramic polymer interpenetrating network material. The Enamic material consists of $75 \%$ feldspathic ceramic matrix, into which an organic phase of dimethacrylate resin containing urethane dimethacrylate and triethylene glycol dimethacrylate is infiltrated [46]. The microstructure has a hybrid structure with interpenetrating networks of ceramic and polymer that mimic the interlocking of prisms in natural teeth. After simulated gastric acid exposure, a porous microstructure with irregularities can be observed.

The microstructure of IPS Empress CAD consisted in a glassy matrix and leucite crystals. The SEM image before exposure shows an interlocking microstructure that remained after exposure, but with the appearance of irregularities and porosities. 
The chemical composition of the elements contained in each material was determined using EDX analysis. Figures 6 and 7 reveal the presence of peak elements recorded at a specific value of amplitude. Table 5 shows the atomic percentage and weight percentage of the recorded elements. According to both Figures 6 and 7 as well as Table 5, after $18 \mathrm{~h}$ of simulated gastric acid solution exposure, the used restorative materials have approximately the same elements as before exposure (data not shown).

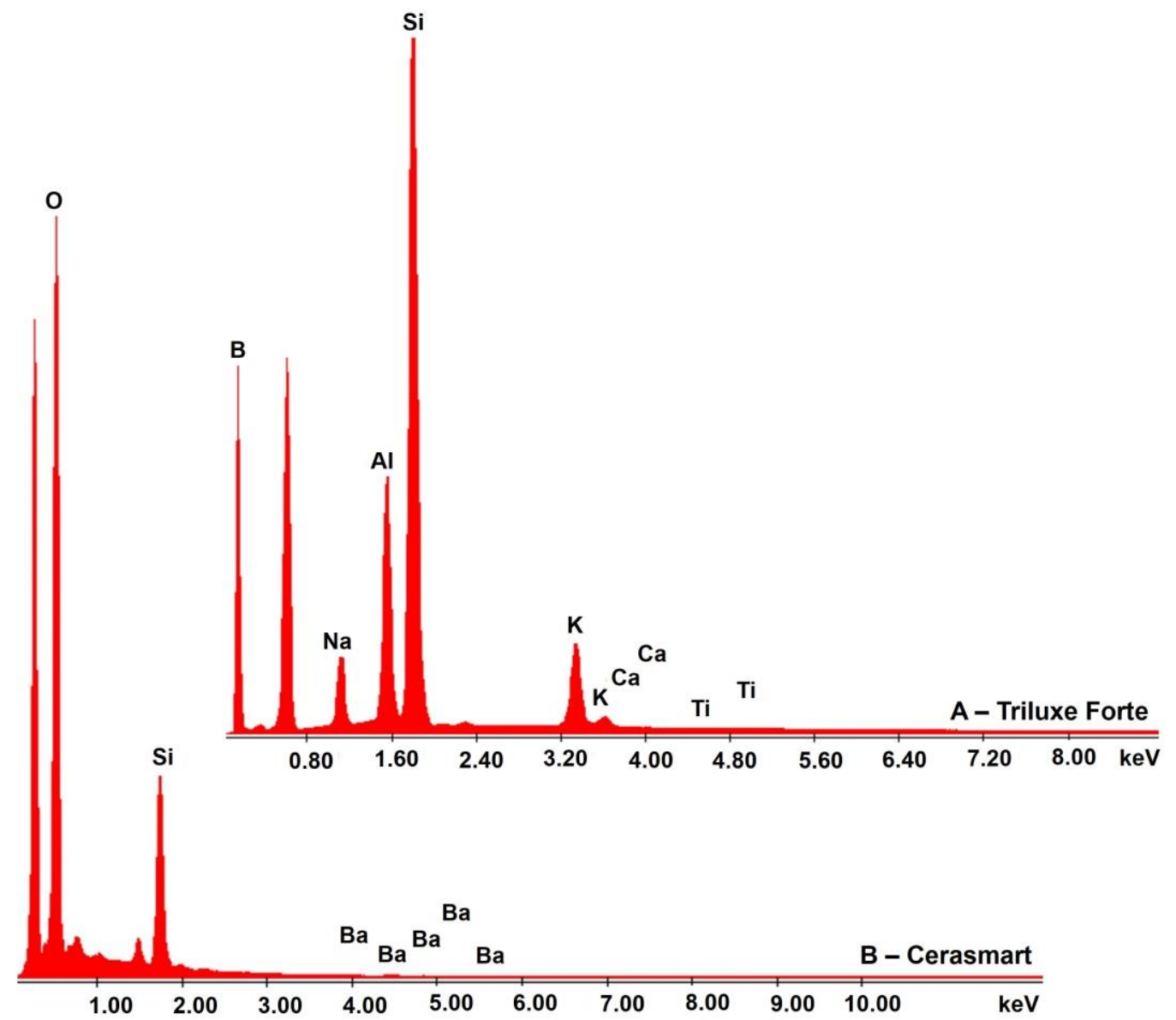

Figure 6. EDX spectra of (A) - Triluxe Forte and (B) - Erasmart restorative materials, after $18 \mathrm{~h}$ of simulated gastric acid solution exposure. 


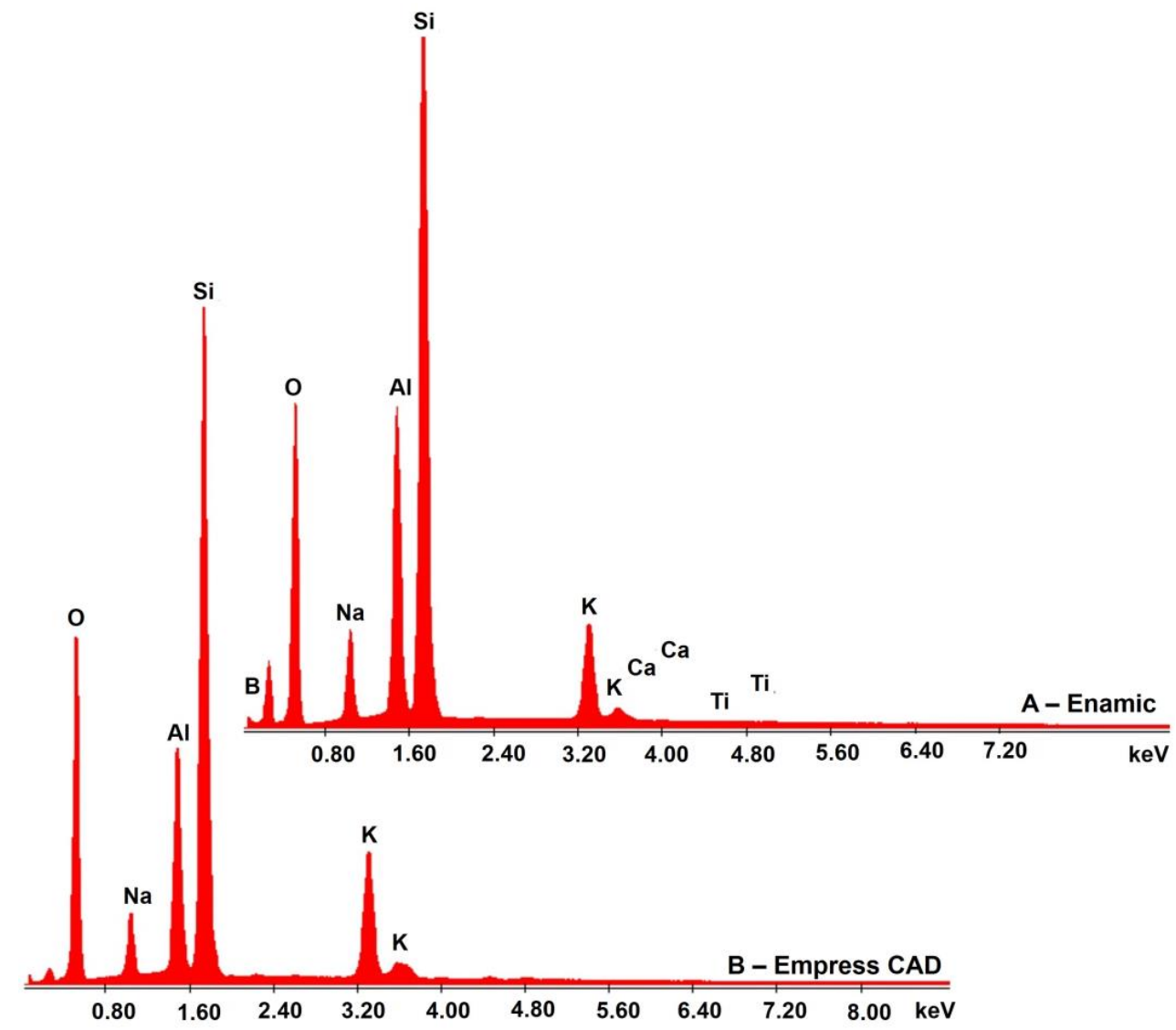

Figure 7. EDX spectra of (A) —Enamic and (B) -Empress CAD restorative materials, after $18 \mathrm{~h}$ of simulated gastric acid solution exposure.

Table 5. The atomic (At) and weight (Wt) percentage values of the elements recorded on EDX spectra.

\begin{tabular}{ccccc}
\hline Material & Element & At [\%] & Wt [\%] & K-Ratio \\
\hline \multirow{5}{*}{ Triluxe Forte } & $\mathrm{B}$ & 97.68 & 94.03 & 0.4133 \\
& $\mathrm{Na}$ & 0.19 & 0.38 & 0.0021 \\
& $\mathrm{Al}$ & 0.46 & 1.11 & 0.0104 \\
& $\mathrm{Si}$ & 1.38 & 3.45 & 0.0360 \\
& $\mathrm{~K}$ & 0.29 & 1.00 & 0.0107 \\
& $\mathrm{Ca}$ & 0.00 & 0.02 & 0.0002 \\
& $\mathrm{Ti}$ & 0.00 & 0.01 & 0.0001 \\
\hline \multirow{5}{*}{ Cerasmart } & $\mathrm{O}$ & 91.01 & 85.22 & 0.07450 \\
& $\mathrm{Si}$ & 8.99 & 14.77 & 0.0001 \\
\hline \multirow{5}{*}{ Enamic } & $\mathrm{Ba}$ & 0.00 & 0.01 & 0.0001 \\
& $\mathrm{~B}$ & 0.00 & 0.02 & 0.1011 \\
& $\mathrm{O}$ & 55.27 & 41.53 & 0.0168 \\
& $\mathrm{Na}$ & 5.61 & 6.06 & 0.0595 \\
& $\mathrm{Al}$ & 2.91 & 32.57 & 0.1612 \\
& $\mathrm{Si}$ & 2.34 & 4.30 & 0.0288 \\
& $\mathrm{~K}$ & 0.07 & 0.14 & 0.0010 \\
& $\mathrm{Ca}$ & 0.02 & 0.03 & 0.1152 \\
& $\mathrm{Ti}$ & 60.52 & 46.55 & 0.0125 \\
Empress & 4.40 & 4.86 & 0.0469 \\
& $\mathrm{O}$ & 7.86 & 32.20 & 0.1541 \\
& $\mathrm{Na}$ & 24.11 & 5.84 & 0.0403 \\
\hline & $\mathrm{Al}$ & 3.11 & &
\end{tabular}

\section{Discussion}

The present study was conducted to evaluate if simulated gastric acid exposure leads to microstructural changes in the surface topography, hardness, color changes and translucency of some ceramic materials that are already on the market. The initial assumption that gastric juices would not affect these materials during $18 \mathrm{~h}$ of exposure was rejected, 
due to the fact that some features of the investigated monolithic materials were affected by the simulated gastric acid solution.

The main objective of restorative dentistry is to replace a lost tooth structure with a material that has optical and mechanical properties that are as close as possible to those of natural tooth. According to Choi and co-workers [47], the mechanical behavior of restorative materials under multiaxial masticatory loading in the oral cavity depends on flexure strengths under different loading conditions. The authors investigated the flexural strengths and elastic properties of resin-composite block materials for CAD/CAM and demonstrated that the strength reliability and the elastic modulus values of the tested materials were significantly different, depending on the testing method, despite the null hypothesis from which they started, namely that there are no differences regarding the flexural and elastic properties of resin-composite CAD/CAM block materials determined by uniaxial and biaxial tests.

It must be also taken into account that oral restorations are exposed to various complex oral conditions during their lifetimes. Dentists review medical histories and medications that identify patients with a diagnosis of acid reflux and they can clinically observe the dental manifestations of gastroesophageal reflux [48]. Gastroesophageal reflux disease is characterized by regular regurgitations of gastric juice from the stomach into the oral cavity [49]. If a patient suffering from gastroesophageal reflux needs a prosthetic restoration, a clinician must take the effect of gastric acid on the restorative material that will be used into account. Resistance to chemical degradation of dental materials is a principal requirement for intra-oral use and represents a decisive factor when choosing the type of the restoration.

The in vitro simulation of the acid on the surface of dental ceramics depends on the concentration of the acid, the time of immersion, and the temperature [48]. In this study, the working $\mathrm{pH}$ was 1.2 and the immersion time was $18 \mathrm{~h}$ at $37^{\circ} \mathrm{C}$. In the literature, there are studies that considered that the simulated gastric acid exposure of CAD-CAM materials for $7.5 \mathrm{~h}$, represent one month of gastric acid exposure, $45 \mathrm{~h}$-represent six months of exposure and $91 \mathrm{~h}$-represent one year of exposure. Backer et al. used CAD-CAM materials exposed to simulated gastric acid for 6 and $18 \mathrm{~h}$, and they calculated that these times represent 2 and 8 years of exposure of dental structure to vomiting [27]. Sulaiman et al. exposed monolithic zirconia to acid solution for $96 \mathrm{~h}$, thus simulating over 10 years of dental structure exposure to vomiting [29]. Evaluating these studies, we can say that, in the literature, there is no clear consensus regarding the method of gastric acid simulation and the equivalent time for replication for an in vivo model. According to ISO standard 6872, which refers to the solubility test for dental materials, the use of $4 \%$ acetic acid and an exposure time of $16 \mathrm{~h}$ at $80^{\circ} \mathrm{C}$ is the equivalent with 2 years of clinical exposure [50].

It is well known that gastric juice has a demineralization effect on enamel, dentin, and cement [28]. Due to its very low $\mathrm{pH}$, it can dissolve the glassy matrix of ceramic materials [31]. In the present study, it was demonstrated that, in the case of feldspathic ceramic, nanoceramic resin, hybrid ceramic, and leucite-reinforced glass ceramic, scanning electron microscopy revealed observable changes in the surface topography after simulated gastric acid exposure for all tested monolithic materials. In the case of Triluxe Forte, the pores and grooves present before immersion were larger after, but there were less irregularities on the material surface. Regarding the Cerasmart material, exposure to simulated gastric acid solution led to increased surface roughness. This phenomena could be explained by the continued leaching of the particles in the presence of the simulated gastric acid solution. The Enamic and Empress CAD materials became more porous with a lot of irregularities. This could be due to the dissolution of the ceramic part contained in the monolithic material or other components [30]. Following analyses on the surface morphology after exposure to simulated gastric acid solution, we can say that Triluxe Forte displayed areas of possible degradation, due to the formed crater-like grooves (Figure 4B). In addition, the porosity of the surfaces leads to an accumulation of bacterial plaque and 
the wear of antagonistic natural teeth. The appearance of pores denotes that exposure to an acidic element will influence the surface of the exposed material [51].

The impact of the simulated gastric acid solution on the optical properties of all four evaluated monolithic materials showed that there were no differences among the specimens, except for Triluxe Forte, which underwent a slight discoloration after exposure to simulated gastric acid. Passing light through a translucent material is reduced by the scattering of small-sized particles, such as filler particles and porosity voids, which can influence color perception and appearance of dental ceramics [52]. In the present study the translucency of the tested materials increased insignificantly after simulated gastric acid exposure and the color values had undergone minor changes, which do not affect the perceptibility and the acceptability thresholds. Cruz et al. obtained the same results, stating that all the ceramic materials tested promoted a color change of $\Delta E<1$, classified as clinically undetectable [30].

The color of a restoration can be affected by a rough surface that reflects an irregular and diffuse pattern of light [53]. According to the results obtained (Table 4), at baseline, leucite-reinforced glass-ceramic showed the lowest surface roughness, while hybrid ceramic showed the highest surface roughness. After $18 \mathrm{~h}$ of immersion in simulated gastric acid solution, the surface characteristics of the hybrid ceramics and leucite glass ceramics did not suffer any significant change.

The simulated gastric acid solution seriously affected the hardness of three of four CAD-CAM monolithic restorative materials, namely, Enamic, Empress CAD, and Triluxe Forte. Among the three restorative materials, once again, Triluxe Forte was most affected, presenting a significant decrease in microhardness after simulated gastric acid exposure.

Our findings, regarding all the investigations are in agreement with the literature data $[28-30,37,54,55]$.

Limitations of the present study include the fact that the materials were not also exposed to saliva to fully mimic the oral environment. Exposing ceramic materials to saliva, as well as gastric acid, might have more closely replicated clinical situations. Another limitation of the current study is that the ceramic discs were not glazed, only polished, which for some materials (i.e., Cerasmart and Enamic) is considered a better finishing method.

\section{Conclusions}

Based on the results of this in vitro study, it can be concluded that there is an increasing need in manufacturing of improve restorative materials, which also comply with the special needs of patients with medical problems, such as gastroesophageal reflux, bulimia, or prolonged severe nausea episodes during pregnancy. For these kinds of patients, the development of materials with good mechanical, optical, physicochemical, and surface topography, will improve their quality of life. The results obtained in this study will help dentists in choosing the best material for patients with other medical problems. In this regard, the results of the present study clearly showed that Triluxe Forte was the CAD-CAM monolithic restorative material that suffered the most important changes after exposure to simulated gastric acid solution (i.e., decrease of hardness, increasing roughness, color change, appearance of pores and irregularities and visualization of crater-like grooves, which means degradation of ceramic part or other components embedded into the material). On the other hand, the Cerasmart monolithic restorative material was proven to be the least affected after simulated gastric acid exposure.

Author Contributions: Conceptualization, I.L.P. and A.J.; methodology, I.L.P., D.P., E.-A.M., C.-V.M. and C.I.; software, D.P., E.-A.M. and C.-V.M.; validation, E.-A.M. and A.J.; formal analysis, I.L.P., D.P., C.-V.M. and C.I..; investigation, I.L.P., D.P., E.-A.M., C.-V.M. and C.I.; resources, A.J.; data curation, I.L.P., D.P., E.-A.M., C.-V.M. and C.I.; writing-original draft preparation, I.L.P.; writing—review and editing, E.-A.M.; visualization, A.J.; supervision, A.J.; project administration, A.J. All authors have read and agreed to the published version of the manuscript.

Funding: This research received no external funding. 
Data Availability Statement: Data presented in this study are available on request from the first author.

Conflicts of Interest: The authors declare no conflict of interest.

\section{References}

1. Mörmann, W.H.; Stawarczyk, B.; Ender, A.; Sener, B.; Attin, T.; Mehl, A. Wear characteristics of current aesthetic dental restorative CAD/CAM materials: Two-body wear, gloss retention, roughness and Martens hardness. J. Mech. Behav. Biomed. Mater. 2013, 20, 113-125. [CrossRef] [PubMed]

2. Gracis, S.; Thompson, V.P.; Ferencz, J.L.; Silva, N.R.; Bonfante, E.A. A new classification system for all ceramic and ceramic-like restorative materials. Int. J. Prosthodont. 2015, 28, 227-235. [CrossRef]

3. Traini, T.; Sinjari, B.; Pascetta, R.; Serafini, N.; Perfetti, G.; Trisi, P.; Caputi, S. The zirconia-reinforced lithium silicate ceramic: Lights and shadows of a new material. Dent. Mater. J. 2016, 35, 748-755. [CrossRef]

4. Sato, T.P.; Anami, L.C.; Melo, R.M.; Valandro, L.F.; Bottino, M.A. Effects of Surface Treatments on the Bond Strength Between Resin Cement and a New Zirconia-reinforced Lithium Silicate Ceramic. Oper. Dent. 2016, 41, 284-292. [CrossRef] [PubMed]

5. Elsaka, S.E.; Elnaghy, A.M. Mechanical properties of zirconia reinforced lithium silicate glass-ceramic. Dent. Mater. 2016, 32, 908-914. [CrossRef] [PubMed]

6. Alves, L.M.M.; Contreras, L.P.C.; Campos, T.M.B.; Bottino, M.A.; Valandro, L.F.; Melo, R.M. In vitro wear of a zirconium-reinforced lithium silicate ceramic against different restorative materials. J. Mech. Behav. Biomed. Mater. 2019, 100, 103403. [CrossRef] [PubMed]

7. Maenosono, R.M.; Brianezzi, L.F.F.; Ishikiriama, S.K.; Furuse, A.Y. Clinical perceptions of zirconia-reinforced lithium silicate ceramic: A case report and 6-month follow-up. Gen. Dent. 2019, 67, 47-50. [PubMed]

8. Curtis, A.R.; Shortall, A.C.; Marquis, P.M.; Palin, W.M. Water uptake and strength characteristics of a nanofilled resin-based composite. J. Dent. 2008, 36, 186-193. [CrossRef]

9. Kim, Y.S.; Kwon, H.K.; Kim, B.I. Effect of nano-carbonate apatite to prevent restain after dental bleaching in vitro. J. Dent. 2011, 39, 636-642. [CrossRef]

10. Ernst, C.P.; Brandenbusch, M.; Meyer, G.; Canbek, K.; Gottschalk, F.; Willershausen, B. Two-year clinical performance of a nanofiller vs. a fine-particle hybrid resin composite. Clin. Oral Investig. 2006, 10, 119-125. [CrossRef]

11. Sauro, S.; Osorio, R.; Watson, T.F.; Toledano, M. Therapeutic effects of novel resin bonding systems containing bioactive glasses on mineral-depleted areas within the bonded-dentine interface. J. Mater. Sci. Mater. Med. 2012, 23, 1521-1532. [CrossRef]

12. De Fúcio, S.B.; Bolzan de Paula, A.; Galbiatti de Carvalho, F.; Pinheiro Feitosa, V.; Ambrosano, G.M.B.; Puppin-Rontani, R.M. Biomechanical degradation of the nano-filled resin-modified glass-ionomer surface. Am. J. Dent. 2012, 25, 315-320.

13. Chen, C.; Trindade, F.Z.; de Jager, N.; Kleverlaan, C.J.; Feilzer, A.J. The fracture resistance of a CAD/CAM Resin Nano Ceramic (RNC) and a CAD ceramic at different thicknesses. Dent. Mater. 2014, 30, 954-962. [CrossRef] [PubMed]

14. Alves, P.B.; Brandt, W.C.; Neves, A.C.; Gonçalves Cunha, L.; Silva-Concilio, L.R. Mechanical properties of direct and indirect composites after storage for $24 \mathrm{~h}$ and 10 months. Eur J. Dent. 2013, 7, 117-122. [PubMed]

15. Belli, R.; Geinzer, E.; Muschweck, A.; Petschelt, A.; Lohbauer, U. Mechanical fatigue degradation of ceramics versus resin composites for dental restorations. Dent. Mater. 2014, 30, 424-432. [CrossRef] [PubMed]

16. Sen, N.; Us, Y.O. Mechanical and optical properties of monolithic CAD-CAM restorative materials. J. Prosthet Dent. 2018, 119, 593-599. [CrossRef] [PubMed]

17. Belli, R.; Wendler, M.; de Ligny, D.; Cicconi, M.R.; Petschelt, A.; Peterlik, H.; Lohbauer, U. Chairside CAD/CAM materials. Part 1: Measurement of elastic constants and microstructural characterization. Dent. Mater. 2017, 33, 84-98. [CrossRef] [PubMed]

18. Lawson, N.C.; Bansal, R.; Burgess, J.O. Wear, strength, modulus and hardness of CAD/CAM restorative materials. Dent. Mater. 2016, 32, 275-283. [CrossRef]

19. Albero, A.; Pascual, A.; Camps, I.; Grau-Benitez, M. Comparative characterization of a novel cad-cam polymer-infiltrated-ceramicnetwork. J. Clin. Exp. Dent. 2015, 7, 495-500. [CrossRef]

20. Acar, O.; Yilmaz, B.; Altintas, S.H.; Chandrasekaran, I.; Johnston, W.M. Color stainability of CAD/CAM and nanocomposite resin materials. J. Prosthet. Dent. 2016, 115, 71-75. [CrossRef]

21. Stawarczyk, B.; Liebermann, A.; Eichberger, M.; Güth, J.F. Evaluation of mechanical and optical behavior of current esthetic dental restorative CAD/CAM composites. J. Mech. Behav. Biomed. Mater. 2016, 55, 1-11. [CrossRef]

22. Karakaya, I.; Cengiz, E. Effect of 2 bleaching agents with a content of high concentrated hydrogen peroxide on stained 2 CAD/CAM blocks and a nanohybrid composite resin: An AFM evaluation. Biomed. Res. Int. 2017, 2017, 6347145. [CrossRef]

23. Jones, L.; Lekkas, D.; Hunt, D.; McIntyre, J.; Rafir, W. Studies on dental erosion: An in vivo-in vitro model of endogenous dental erosion-Its application to testing protection by fluoride gel application. Aust. Dent. J. 2002, 47, 304-308. [CrossRef] [PubMed]

24. Turssi, C.P.; Hara, A.T.; de Magalhaes, C.S.; Campos Serra, M.; Rodrigues Jr, A.L. Influence of storage regime prior to abrasion on surface topography of restorative materials. J. Biomed. Mater. Res. B Appl. Biomater. 2003, 65, 227-232. [CrossRef] [PubMed]

25. Yu, H.; Wegehaupt, F.J.; Wiegand, A.; Roos, M.; Attin, T.; Buchalla, W. Erosion and abrasion of tooth-colored restorative materials and human enamel. J. Dent. 2009, 37, 913-922. [CrossRef] [PubMed]

26. Matsou, E.; Vouroutzis, N.; Kontonasaki, E.; Paraskevopoulos, K.M.; Koidis, P. Investigation of the influence of gastric acid on the surface roughness of ceramic materials of metal-ceramic restorations. An in vitro study. Int. J. Prosthodont. 2011, 24, 26-29. [PubMed] 
27. Backer, A.D.; Münchow, E.A.; Eckert, G.J.; Hara, A.T.; Platt, J.A.; Bottino, M.C. Effects of simulated gastric juice on CAD/CAM resin composites-morphological and mechanical evaluations. J. Prosthodont. 2017, 26, 424-443. [CrossRef]

28. Bartlett, D.W.; Coward, P.Y. Comparison of the erosive potential of gastric juice and a carbonated drink in vitro. J. Oral Rehabil. 2001, 28, 1045-1047. [CrossRef]

29. Sulaiman, T.A.; Abdulmajeed, A.A.; Shahramian, K.; Hupa, L.; Donovan, T.E.; Vallittu, P.; Närhi, T.O. Impact of gastric acidic challenge on surface topography and optical properties of monolithic zirconia. Dent. Mater. 2015, 31, 1445-1452. [CrossRef]

30. Cruz, M.E.M.; Simoes, R.; Martins, S.B.; Trinidade, F.Z.; Dovigo, L.N.; Fonseca, R.G. Influence of simulated gastric juice on surface characteristics of CAD-CAM monolithic materials. J. Prosthet Dent. 2020, 123, 483-490. [CrossRef]

31. Harryparsad, A.; Dullabh, H.; Sykes, L.; Herbst, D. The effects of hydrochloric acid on all-ceramic restorative materials: An in-vitro study. SADJ 2014, 69, 106-111.

32. Castillo, M.; Weiselberg, E. Bulimia nervosa/purging disorder. Curr. Probl. Pediatr. Adolesc. Health Care 2017, 47, 85-94. [CrossRef]

33. Sengupta, A. Dental Erosion: Etiology, Diagnosis and Management. Acta Sci. Dent. Sci. 2018, 2, $43-48$.

34. Haq, M.W.; Batool, M.; Ahsan, S.H.; Lone, M.A.; Islam, T. Dental erosion: Influencing factors \& pH analysis. Can. J. Appl. Sci. 2012, 2, 222-232.

35. Zhang, J.; Du, Y.; Wei, Z.; Tai, B.; Jiang, H.; Du, M. The prevalence and risk indicators of tooth wear in 12- and 15-year-old adolescents in Central China. BMC Oral Health. 2015, 15, 120. [CrossRef] [PubMed]

36. Theocharidou, A.; Kontonasaki, E.; Koukousaki, I.; Koumpouli, A.; Betsani, I.; Koidis, P. Effect of in vitro aging and acidic storage on color, translucency, and contrast ratio of monolithic zirconia and lithium disilicate ceramics. J. Prosthet. Dent. 2021, 3913, 30805-30815.

37. Kulkarni, A.; Rothrock, J.; Thompson, J. Impact of Gastric Acid Induced Surface Changes on Mechanical Behavior and Optical Characteristics of Dental Ceramics. J. Prosthodont. 2020, 29, 207-218. [CrossRef] [PubMed]

38. Egilmez, F.; Ergun, G.; Cekic-Nagas, I.; Vallittu, P.K.; Lassila, L.V.J. Does artificial aging affect mechanical properties of CAD/CAM composite materials. J. Prosthodont. Res. 2018, 62, 65-74. [CrossRef]

39. Kaur, S.; Makkar, S.; Kumar, R.; Pasricha, S.; Gupta, P. Comparative evaluation of surface properties of enamel and different esthetic restorative materials under erosive and abrasive challenges: An in vitro study. Indian J. Dent. 2015, 6, 172-180.

40. Zaki, D.Y.I.; Hamzawy, E.M.A.; El Halim, S.A.; Amer, M.A. Effect of simulated gastric juice on surface characteristics of direct esthetic restorations. Aust. J. Basic Appl. Sci. 2012, 6, 686-694.

41. Cengiz, S.; Sarac, S.; Özcan, M. Effects of simulated gastric juice on color stability, surface roughness and microhardness of laboratory-processed composites. Dent. Mater. J. 2014, 33, 343-348. [CrossRef] [PubMed]

42. Bakar, W.Z.W.; McIntyre, J. Susceptibility of selected tooth-coloured dental materials to damage by common erosive acids. Aust. Dent. J. 2008, 53, 226-234. [CrossRef] [PubMed]

43. de Carvalho Panzeri Pires-de-Souza, F.; Assirati Casemiro, L.; da Fonseca Roberti Garcia, L.; Rodrigues Cruvinel, D. Color stability of dental ceramics submitted to artificial accelerated aging after repeated firings. J. Prosthet. Dent. 2009, 101, 13-18. [CrossRef]

44. Pires, L.A.; Novais, P.M.; Araújo, V.D.; Pegoraro, L.F. Effects of the type and thickness of ceramic, substrate, and cement on the optical color of a lithium disilicate ceramic. J. Prosthet Dent. 2017, 117, 144-149. [CrossRef] [PubMed]

45. Salas, M.; Lucena, C.; Javier Herrera, L.; Yebra, A.; Della Bona, A.; Pérez, M.M. Translucency thresholds for dental materials. Dent. Mater. 2018, 34, 1168-1174. [CrossRef] [PubMed]

46. Zhang, Y.; Kelly, J.R. Dental Ceramics for Restoration and Metal Veneering. Dent. Clin. N. Am. 2017, 61, 797-819. [CrossRef]

47. Choi, B.J.; Yoon, S.; Im, I.W.; Lee, J.H.; Jung, H.J.; Lee, H.H. Uniaxial/biaxial flexure strengths and elastic properties of resincomposite block materials for CAD/CAM. Dent. Mater. 2019, 35, 389-401. [CrossRef]

48. Aldamaty, M.F.; Haggag, K.M.; Othman, H.I. Effect of simulated gastric acid on surface roughness of different monolithic ceramics. Al-Azhar J. Dent. Sci. 2020, 23, 327-334. [CrossRef]

49. El-Serag, H.B.; Sweet, S.; Winchester, C.C.; Dent, J. Update on the epidemiology of gastro-oesophageal reflux disease: A systematic review. Gut 2014, 63, 871-880. [CrossRef]

50. International Organization for Standardization. International Standards for Dental Ceramics; ISO 6872; International Organization for Standardization: Geneva, Switzerland, 1995.

51. Carvalho Ramos, N.; Campos, T.M.; Paz, I.S.; Machado, J.P.; Bottino, M.A.; Cesar, P.F.; de Melo, R.M. Microstructure characterization and SCG of newly engineered dental ceramics. Dent. Mater. 2016, 32, 870-878. [CrossRef]

52. Della Bona, A.; Nogueira, A.D.; Pecho, O.E. Optical properties of CAD-CAM ceramic systems. J. Dent. 2014, 42, 1202-1209. [CrossRef] [PubMed]

53. Sarac, D.; Sarac, Y.S.; Yuzbasioglu, E.; Bal, S. The effects of porcelain polishing systems on the color and surface texture of feldspathic porcelain. J. Prosthet. Dent. 2006, 96, 122-128. [CrossRef] [PubMed]

54. Kukiattrakoon, B.; Hengtrakool, C.; Kedjarune-Leggat, U. Chemical durability and microhardness of dental ceramics immersed in acidic agents. Acta Odontol. Scand. 2010, 68, 1-10. [CrossRef] [PubMed]

55. Zakir, T.; Dandekeri, S.; Suhaim, K.S.; Shetty, N.H.G.; Ragher, M.; Shetty, S.K. Influence of aerated drink, mouthwash, and simulated gastric acid on the surface roughness of dental ceramics: A comparative in Vitro study. J. Pharm. Bioallied. Sci. 2020, 12, S480-S4871. 